\title{
Por que é preciso aprofundar o conceito de gêneros do discurso?
}

Fernanda Lopes Bortolini* Patrícia da Silva Valério**

\section{Resumo}

Este artigo assume como objetivo revisitar o conceito de gênero do discurso, sob a perspectiva do Círculo de Bakhtin, para, por meio dessa incursão teórica, aprofundar o conceito de gênero em um conjunto de textos, para além do manuscrito clássico que o popularizou. O estudo revela que o conceito de gênero do discurso para Bakhtin e o Círculo assume a estrutura triádica - conteúdo temático, construção composicional e estilo, como parte essencial do conceito, mas outros elementos devem ser levados em consideração, como o contexto de produção do gênero, a esfera de atividade humana em que está ancorado o discurso que se materializa nos gêneros, os sujeitos envolvidos na interação, o auditório social, as relações dialógicas constitutivas do enunciado.

Palavras-chave: Gêneros do discurso; relações dialógicas; interação; enunciado.

\section{Considerações iniciais}

É inegável a grande mobilização e leitura do conceito de gênero do discurso de Mikhail Bakhtin e o Círculo, especialmente a partir dos anos 1970, quando o autor e suas obras passam pelo processo de (re)descoberta na União Soviética e de descoberta no Ocidente. No Brasil, a circulação do conceito de gênero é intensa, revelando um caráter de "uso inflacionado", conforme metaforiza Faraco (2009). A amplitude do emprego desse conceito se deve, primeiramente, à apropriação que o discurso pedagógico fez e faz, por meio de materiais didáticos e documentos oficiais norteadores da educação básica. Além disso, o conceito circula amplamente em muitas pesquisas realizadas sob a perspectiva dos gêneros discursivos, revelando a

\footnotetext{
* Mestra em Letras pela Universidade de Passo Fundo. E-mail: lopesbortolinifernanda@gmail.com

** Doutora em Linguística Aplicada. Docente do Curso de Letras e do Programa de Pós-graduação em Letras da Universidade de Passo Fundo. E-mail: patriciav@upf.br
}

Data de submissão: abr. 2021 - Data de aceite: jul. 2021 http://dx.doi.org/10.5335/rdes.v17i2.12587 
amplitude alcançada por esse "arcabouço teórico-prático denominado gênero" (BRAIT; PISTORI, 2012, p. 371).

No que se refere ao conceito de gênero do discurso, sabemos que o manuscrito mais citado e, por vezes, tomado como único sobre o tema, encontra-se no texto esboçado por Bakhtin nos anos 1952-1953, "Os gêneros do discurso", e incluído na coletânea póstuma Estética da Criação verbal (1979). No entanto, é importante mencionar que tal escrito não é o único a tratar do tema. Corroborando essa afirmativa, Brait e Pistori (2012, p. 374) revelam que "a maioria dos leitores acaba entendendo gênero do discurso como uma fórmula mágica, reduzida somente a três elementos: forma composicional, conteúdo temático e estilo", e que uma vez aplicada, essa receita dará conta da compreensão e do ensino de gêneros e, consequentemente, de leitura e produção de textos.

Este artigo convida o leitor a considerar o conceito amplo de gênero que, na compreensão que defendemos, não se reduz apenas ao conceito triádico, presente no escrito clássico. Defendemos que há uma concepção de língua anterior à concepção de gênero e que esta vai sendo construída ao longo dos trabalhos do Círculo de Bakhtin. Tal perspectiva nos provoca a realizar uma leitura enfocando os gêneros discursivos, ainda que alguns textos reflitam sobre os gêneros advindos da literatura, como propuseram Brait e
Pistori (2012). Consideramos importante que os linguistas e analistas do discurso realizem a leitura dos textos, enfocando questões dos gêneros discursivos.

Nesse sentido, ao constatarmos a circulação intensa do conceito de gênero do discurso no Brasil, porém, enfocando o tema a partir do texto "Os gêneros do discurso", mapeamos outros textos e obras em que o Círculo de Bakhtin se debruça a estudar temas como gêneros discursivos, interação discursiva, relações dialógicas, enunciado concreto, noções que, entre si, estabelecem relações de sentido e potencializam a compreensão do conceito de gêneros do discurso. Interessa-nos neste artigo, portanto, revelar nossa incursão teórica em busca de aprofundar o conceito de gênero, percebendo como esse conceito se constrói ao longo dos trabalhos do Círculo.

Para realização dessa incursão teórica, mobilizamos escritos do Círculo de Bakhtin, a saber ${ }^{1}$ M. M. Bakhtin (1924; 2010[1975]; 2016 [1952-1953]); P. Medviédev, (2016[1928]); e V. Volóchinov, (2017[1929]). Além dos autores russos, apoiamo-nos em leituras de Faraco (2013) e Brait e Pistori (2012).

Dessa forma, este artigo está estruturado em cinco seções, as quais buscam, no conjunto, contribuir para a compreensão do conceito de gênero, além das considerações finais e esta introdução. Assim, na primeira seção, tratamos da questão da dupla orientação do gênero 
na realidade, a partir da obra Método formal nos estudos literários: uma introdução crítica a uma poética sociológica, escrita por Pável N. Medviédev, interessando-nos especialmente, pelo texto "Os elementos da construção artística". Na segunda seção, mobilizamos os conceitos de forma arquitetônica e forma composicional do gênero, recorrendo ao texto "O problema do conteúdo, do material e da forma na criação literária”, de 1924. $\mathrm{Na}$ terceira seção, tratamos das noções intrínsecas de gênero e discurso, que se constituem em um campo dialógico, a partir da leitura dos capítulos "Peculiaridade do gênero, do enredo e da composição das obras de Dostoiévski” e "O discurso em Dostoiévski", da obra Problemas da Poética de Dostoiévski, publicada em 1963. Na seção quatro, discutimos a noção de enunciado como totalidade e suas formas, a partir dos capítulos "O problema da relação entre a base e a superestrutura", e "A interação discursiva", da obra Marxismo e Filosofia da Linguagem: problemas fundamentais do método sociológico na ciência da linguagem, de 1929. Na seção cinco, voltamo-nos ao texto clássico, "Os gêneros do discurso", para realizar uma incursão acerca do conceito de gêneros do discurso mobilizado, sobretudo, no que se refere à estrutura triádica dos gêneros do discurso e, ainda, ao estudo do enunciado concreto, como a realidade fundamental da comunicação discursiva.
A seguir, passamos à incursão teórica acerca do conceito de gênero do discurso.

\section{A dupla orientação do gênero na realidade}

Iniciamos a reflexão sobre os gêneros do discurso, a partir da obra Método formal nos estudos literários: uma introdução crítica a uma poética sociológica, escrita por Pável N. Medviédev, um dos intelectuais integrantes do Círculo de Bakhtin. Dentre os capítulos que compõem o livro, interessa-nos o capítulo terceiro - "Os elementos da construção artística" -, subdividido em oito partes, situado na terceira parte do livro, que trata especificamente do tema gênero.

Ao contrário do que prega o senso comum pedagógico, o conceito de gêneros discursivos não surge no manuscrito homônimo de Bakhtin, escrito provavelmente no final da década de 50 . De acordo com Morson e Emerson (2008), o caráter embrionário da discussão de gêneros encontra-se presente na obra de Medviédev, publicada em 1928:

talvez ainda mais surpreendente, a primeira discussão séria do grupo de Bakhtin, em torno do gênero pertence não ao próprio Bakhtin, mas a Medviédev, que reserva um capítulo para demonstrar que uma boa abordagem sociológica da literatura deve "estribar-se" nos gêneros, que contêm e moldam a experiência social para pessoas individuais (MORSON; EMERSON, 2008, p. 287). 
Para fundamentar o conceito de gênero, Medviédev (2016[1928]) destaca que os formalistas definem o gênero como agrupamento específico e constante de procedimentos com determinada dominante, em que os procedimentos fundamentais são motivados fora do gênero, e enfatiza: "o significado atual do gênero não foi compreendido pelos formalistas" (MEDVIÉDEV, 2016[1928]), p. 193).

Na perspectiva do Círculo de Bakhtin,

[...] o gênero é uma forma típica do todo da obra, do todo do enunciado. Uma obra só se torna real quando toma a forma de determinado gênero (MEDVIÉDEV, 2016[1928], p. 193).

E, ainda, "o gênero é uma totalidade típica do enunciado artístico, e uma totalidade essencial, acabada e resolvida" (MEDVIÉDEV, 2016[1928], p. 193).

Sobre o conceito de gênero desenvolvido por Medviédev nessa obra, Brait e Pistori (2012, p. 382) nos alertam: "o leitor não deve se enganar. Embora os títulos, da obra e do capítulo, sugiram a ideia de estudos exclusivamente literários, a discussão passa por questões fundamentais para a compreensão do gênero do discurso de forma geral".

As pesquisadoras complementam que, ao realizar tal afirmação,

Medviédev constrói o contexto teórico-metodológico em que a proposição sobre gênero está ancorada, contrapondo-se ao estudo do gênero entrevisto unicamente por meio de elementos formais da língua e propondo sua compreensão a partir da totalidade da obra/ enunciado (BRAIT; PISTORI, 2012, p. 382).
Surge, assim, uma nova perspectiva sobre o gênero: o ponto de vista da totalidade do enunciado.

Medviédev (2016[1928]) argumenta que a totalidade artística de qualquer enunciado - isto é, de qualquer gênero do discurso - orienta-se de forma dupla, e que as peculiaridades dessa dupla orientação determinam a totalidade do gênero. $\mathrm{O}$ que destacamos é que uma das características essenciais do gênero, nessa perspectiva, é que este se define a partir da dupla orientação na realidade, em que a primeira orientação está ligada à exterioridade do gênero, ou conforme postula Medviédev:

Na primeira orientação a obra entra em um espaço e tempo real. [..]. A obra ocupa certo lugar na existência, está ligada ou próxima a alguma esfera ideológica. [...]. Desse modo, uma obra entra na vida e está em contato com os diferentes aspectos da realidade circundante mediante o processo de sua realização efetiva, como executada, ouvida, lida em determinado tempo, lugar e circunstância. Ela ocupa certo lugar, que é concedido pela vida, enquanto corpo sonoro real. Esse corpo está disposto entre as pessoas que estão organizadas de determinadas formas (MEDVIÉDEV, 2016 [1928], p. 195, grifo nosso).

Essa primeira orientação da realidade, a de exterioridade, está ligada à vida, que está ligada a um tempo, a um espaço e a uma esfera ideológica em que o gênero está situado. Brait e Pistori (2012, p. 383) complementam que 
[...] o enunciado como totalidade se produz num espaço e num tempo reais, podendo ser oral ou escrito, implicando a existência de um auditório de receptores, destinatários, ouvinte e/ou leitores.

A segunda orientação da realidade refere-se à interioridade - determinação interna e temática - dos gêneros. Como afirma Medviédev (2016[1928], p. 196):

[..] cada gênero é capaz de dominar somente determinados aspectos da realidade, ele possui certos princípios de seleção, determinadas formas de visão e de compreensão dessa realidade, certos graus de extensão de sua apreensão e na profundidade de penetração nela.

Isto é, a interioridade dos gêneros está ligada à forma, à estrutura e ao conteúdo temático do enunciado em uma determinada esfera ideológica.

Nessa perspectiva, para conceber os gêneros do discurso,

[...] é necessário considerar as circunstâncias temporais, espaciais, ideológicas que orientam o discurso e o constituem, assim como os elementos linguísticos, enunciativos, formais que possibilitam a sua existência (BRAIT e PISTORI, 2012, p. 383).

Eis a dupla orientação do gênero na realidade desenvolvida por Medviédev.

Em síntese, nesse capítulo, Medviédev (2016[1928]) constrói uma perspectiva de gênero como totalidade do enunciado e essa totalidade se efetiva pela dupla orientação do gênero na realidade. Importante compreender que entre a primeira e a segunda orientação são estabelecidas uma ligação e uma inter- dependência indissolúvel, em que uma parte se determina pela outra, tornando-se uma ação única, porém bilateral. Além disso, o gênero é um conjunto de meio de orientação coletiva dentro de uma determinada realidade, por meio do qual é possível compreender novos aspectos da realidade, e nossa visão e compreensão da realidade se realiza no processo de comunicação social. Isto é, "O gênero lança uma luz sobre a realidade, enquanto a realidade ilumina o gênero" (MEDVIÉDEV, 2016[1928], p. 201).

Desenvolvida a questão do gênero como totalidade, revelando a dupla orientação da realidade, passamos à apresentação do conceito de forma arquitetônica e forma composicional do gênero.

\section{Sobre a forma}

\section{arquitetônica e a forma composicional do gênero}

Nesta seção, a fim de mobilizarmos os conceitos de forma arquitetônica e forma composicional do gênero, recorremos ao texto "O problema do conteúdo, do material e da forma na criação literária”, de 1924.

Bakhtin (2010[1924]) arrola, nesse texto, cinco pontos que considera comprometedores à estética material, e a partir deles constrói sua crítica e sua superação conceitual. Os pontos são: a) a estética material é incapaz de estabe- 
lecer os fundamentos da forma artística; b) é incapaz de estabelecer os fundamentos da diferença essencial entre o objeto estético e a obra externa (o artefato); c) confunde a forma arquitetônica e a forma composicional; d) é incapaz de explicar o esteticismo; e) é incapaz de fundamentar a história da arte. Porém, nos revela Faraco (2013, p. 103), que,

[...] apesar disso tudo, Bakhtin considera que o método formal não é de todos descartável. [...] Tal método pode ser muito produtivo no estudo da técnica de criação artística.

Dentre os cincos pontos arrolados por Bakhtin (2010[1924]), um, em especial, contribui para o conceito de gênero do discurso, que é o que se refere à forma composicional e à forma arquitetônica:

As formas arquitetônicas são as formas dos valores morais e físicos do homem estético, as formas da natureza enquanto seu ambiente, as formas do acontecimento no seu aspecto de vida particular, social, histórica, etc.; todas elas são aquisições, realizações, não servem nada, mas se auto-satisfazem [sic] tranquilamente; são as formas da existência estética na singularidade. [...]. As formas composicionais organizam o material e têm um caráter teleológico, utilitário, como que inquieto, e estão sujeitas a uma avaliação puramente técnica, para determinar quão adequadamente realizam a tarefa arquitetônica (BAKHTIN, 2010[1924], p. 24-25, grifo nosso).

Brait e Pistori (2012, p. 378) nos ajudam a compreender o que o pensador russo postula:
Bakhtin sugere que é preciso enfrentar a unidade do texto não como dada exclusivamente por sua forma externa, aparentemente autônoma, mas por seu plano, ou seja, por suas condições concretas de vida, suas interdependências, suas relações, suas posições dialógicas e valorativas.

Isto é, o enunciado corporifica-se em uma determinada forma arquitetônica e composicional, surge como um acontecimento, em uma determinada interação discursiva, que é sempre social.

Bakhtin (2010[1924]) aponta que a forma arquitetônica determina a escolha da forma composicional e exemplifica com o gênero prosaístico romance, que é uma forma puramente composicional de organização de massas verbais e, por essa forma, constitui-se em um objeto estético.

Nessa perspectiva, o estudo do gênero deve adotar uma concepção que considere a forma arquitetônica e a forma composicional. É necessário levar em conta, nessa perspectiva, as dimensões (interna e externa) do texto, de forma a explicitar as relações dialógicas e valorativas implicadas, isso é, deve-se estudá-lo como produção de linguagem, situada, e não somente como formas linguísticas (BRAIT; PISTORI, 2012).

Definidos os conceitos de forma arquitetônica e forma composicional como elementos importantes à compreensão do conceito de gênero do discurso para o Círculo de Bakhtin, voltemo-nos, na próxima seção, à necessária articulação entre gênero e discurso. 


\section{A necessária articulação entre gênero e discurso: o discurso se constrói em um campo dialógico}

A seção a seguir trata sobre as noções intrínsecas de gênero e discurso, que se constituem em um campo dialógico. Para dar conta dessa abordagem, lemos os capítulos "Peculiaridade do gênero, do enredo e da composição das obras de Dostoiévski" e "O discurso em Dostoiévski”, que estão na obra Problemas da Poética de Dostoiévski, publicada em 1963.

No capítulo intitulado "Peculiaridade do gênero, do enredo e da composição das obras de Dostoiévski”, interessa-nos o excerto em que Bakhtin (2013[1963], p. 136) enfoca que "o parentesco entre esses gêneros [...] é determinado pelo seu caráter dialógico interno e externo no enfoque da vida e do pensamento humanos". A partir da leitura desse excerto, Brait e Pistori (2012) revelam que o caráter dialógico interno e externo no enfoque da vida e do pensamento é de suma importância à compreensão do conceito de gênero do discurso para $o$ Círculo de Bakhtin, pois

[...] o conceito de gênero não se limita a estruturas ou textos, embora os considere como dimensões constituintes. Implica, essencialmente, dialogismo e maneira de entender e enfrentar a vida (BRAIT e PISTORI, 2012, p. 375).
Isto é, os gêneros do discurso são constituídos de dialogismo interno, ao convocarem outros textos advindos de uma mesma tradição de gênero. Os gêneros são constituídos nas relações dialógicas estabelecidas e evocam discursos em determinadas interações discursivas, em uma perspectiva dialógica de linguagem.

Ainda sobre o caráter dialógico interno e externo, Bakhtin aponta outro elemento importante sobre a tradição dos gêneros literários, mas também dos gêneros de discurso.

O gênero sempre conserva elementos imorredouros da archaica. É verdade que nele essa archaica só se conserva graças à sua permanente renovação, vale dizer, graça à atualização. $\mathrm{O}$ gênero sempre é e não é o mesmo, sempre é novo e velho ao mesmo tempo. [...] Nisso consiste a vida do gênero. Por isso, não é morta nem a archaica que se conserva no gênero; ela é eternamente viva, ou seja, é uma archaica com capacidade de renovar-se. $\mathrm{O}$ gênero vive do presente, mas sempre recorda o seu passado, o seu começo (BAKHTIN, 2013[1963], p. 121, grifos do autor).

Isto é, o gênero está ligado a uma tradição clássica, de um gênero clássico, no entanto, está sempre em constante atualização, pois se renova a cada nova utilização, a cada novo surgimento de um gênero do discurso, construído de relações dialógicas. Nesse sentido, os gêneros constituem-se de relações internas e externas dialógicas ao superarem a archaica e se renovam a partir de um novo contexto social de surgimento. 
Sobre esse ponto, Brait e Pistori (2012) registram a tradição em que se inserem os gêneros, pois a partir dessa perspectiva teórico-metodológica é que se pode realizar estudos sobre os gêneros em perspectiva diacrônica - estudar os gêneros antecedentes a que eles se ligam e modificam - e sincrônica - estudar as características pertencentes aos gêneros antecessores e às novas características dos gêneros atuais advindos dessa tradição (BRAIT e PISTORI, 2012).

Em outro capítulo, "O discurso em Dostoiévski”, Bakhtin (2013[1963]) realiza uma reflexão no que se refere à linguagem e ao discurso na prosa literária. Logo no início do capítulo, Bakhtin (2013[1963]) ao conceituar discurso, revela que objeto que ele vai mobilizar é um "fenômeno concreto, muito complexo e multifacetado - o discurso" (BAKHTIN, 2013[1963], p. 207). Revela, com isso, preocupar-se com a língua em sua concretude, isto é, com a língua em uso. Para Brait e Pistori (2012), essa afirmação revela uma dupla contribuição do texto ao conceito de gênero: que o conceito de gênero em Bakhtin não se limita aos literários e faz-se necessária uma articulação entre gênero e discurso.

Para Bakhtin (2013[1963]), o discurso se constrói em um campo dialógico, porém, na perspectiva da linguagem como objeto da Linguística, não há nem pode haver qualquer relação dialógica, nem entre os elementos da língua, nem entre elementos dos textos. Para o pensador russo,

[...] as relações dialógicas são extralinguísticas. Ao mesmo tempo, porém, não podem ser separadas do campo do discurso, isto é, da língua como fenômeno integral concreto (BAKHTIN, 2013[1963], p. 209).

E o filólogo complementa que

[...] as relações dialógicas devem personificar-se na linguagem, tornar-se enunciados, converter-se em posições de diferentes sujeitos expressa na linguagem para que entre eles possam surgir relações dialógicas (BAKHTIN, 2013[1963], p. 209).

Essa compreensão revela que a linguagem como fenômeno integral concreto se realiza por meio de enunciados concretos, ou seja, de gêneros de discursos, de distintas esferas discursivas, que surgem em práticas sociais de interações comunicativas e se orientam nas relações dialógicas que os perpassam.

Explanada a necessária articulação que se deve estabelecer entre gêneros e o discurso, isto é, a língua em sua integridade concreta e viva, e não unicamente como objeto da Linguística, conceito importante para nossa releitura do conceito de gêneros de discurso, sob a perspectiva do Círculo Bakhtin, passamos, a seguir, à leitura e reflexão sobre o conceito de enunciado como totalidade e as suas formas. 


\section{$\mathrm{O}$ enunciado como totalidade e suas formas}

Na presente seção discutimos a noção de enunciado como totalidade e suas formas, os gêneros do discurso, a partir do capítulo 2 , "O problema da relação entre a base e a superestrutura", da primeira parte, e em um segundo momento, na segunda parte, no capítulo 3, "A interação discursiva". Nesse sentido, voltemo-nos aos dois textos da obra Marxismo e Filosofia da Linguagem: problemas fundamentais do método sociológico na ciência da linguagem, de 1929, sob a autoria de Valentin Volóchinov.

Ao longo do capítulo intitulado "O problema da relação entre a base e a superestrutura", Volóchinov (2017a[1929]) argumenta sobre a correlação entre a formação da sociedade e a formação da palavra, mostrando que o signo reflete e refrata a sociedade. O texto faz uma reflexão sobre a especificidade da palavra - signo ideológico por excelência - e suas peculiaridades, ao afirmar que mais importante que sua natureza sígnica é a sua onipresença social, em que ela participa de toda interação e todo contato entre pessoas. Além disso, na palavra se realizam os fios ideológicos que se penetram na comunicação social e a palavra é assumida como um potente indicador de mudanças sociais.

O teórico assume que o elo entre a base e as superestruturas se dá na psi- cologia social - conceito que advém dos estudos marxistas - e tal elo é assumido com um meio dos discursos verbais. A psicologia social é assumida como um campo enorme de comunicação ideológica que não pode ser atribuído a uma esfera ideológica específica, isto é, refere-se à comunicação cotidiana a qual se materializa na interação verbal de uma coletividade organizada. E a psicologia social só passa a existir na exterioridade impressa no material da palavra, que se concretiza na forma de enunciados, ou em modo de pequenos gêneros discursivos (VOLÓCHINOV, 2017a[1929]).

Volóchinov, ao situar o papel da psicologia social na interação discursiva, ressalta que até 1929 esta era estudada apenas sob o ponto de vista do seu conteúdo, ou seja, pelo prisma dos temas. No entanto, o autor convoca uma perspectiva em que se estude de um segundo ponto de vista, o das "formas e tipos de comunicação discursiva em que esses temas se realizam" (VOLÓCHINOV, 2017a[1929], p. 108, grifos do autor). Ou seja, esse segundo ponto de vista refere-se aos gêneros discursivos e sua tipologia que, como destaca o teórico, até o momento não havia sido objeto de estudos marxistas, embora estejam intimamente ligados.

O teórico russo reconhece que as formas da comunicação discursiva, as formas do enunciado e o tema constituem uma unidade orgânica e ininterrupta, 
e "a classificação das formas do enunciado deve apoiar-se na classificação das formas de comunicação discursiva" (VOLÓCHINOV, 2017a, p. 109, grifos do autor). Tais formas de comunicação discursiva - os gêneros do discurso - são determinadas pela base, pelas formas de comunicação social utilizadas e pela organização hierárquica da sociedade, assim os processos de interações discursivas constroem-se no aspecto hierárquico. O que o teórico nos revela que é todo signo ideológico surge entre os indivíduos socialmente organizados no processo de interação discursiva e, portanto, "as formas do signo são condicionadas, antes de tudo, tanto pela organização social desses indivíduos quanto pelas condições mais próximas da sua interação" (VOLÓCHINOV, 2017a[1929], p. 109, grifos do autor).

Em suma, nessa primeira parte, Volóchinov (2017[1929]) estabelece as relações entre a filosofia da linguagem e o estudo das ideologias sob a perspectiva da psicologia social, como universo do discurso verbal, que se realiza na forma de enunciados, que se constituem em gêneros discursivos do cotidiano e que se realizam na interação discursiva. $\mathrm{Ou}$ seja, é a palavra como signo ideológico e como mediadora da comunicação social.

No outro capítulo, "A interação discursiva”, Volóchinov (2017b[1929]) retoma e amplia considerações acerca das categorias de discursos verbais na vida e na ideologia do cotidiano e interação discursiva, a fim de elaborar uma sociologia marxista da linguagem. $\mathrm{O}$ autor define que

[...] todo o conjunto de vivências da vida e da expressão externas ligadas diretamente a elas chamaremos, diferentemente dos signos ideológicos formados - a arte, a moral, o direito -, de ideologia do cotidiano (VOLÓCHINOV, 2017b[1929], p. 213).

Ainda que a ideologia do cotidiano seja "o universo do discurso interior e exterior não ordenado nem fixado" (2017b[1929], p. 213), é a partir do caráter sociológico da estrutura da expressão e da vivência que o autor confirma que a ideologia do cotidiano corresponde geralmente àquilo que na literatura marxista é denominado de psicologia social.

Nessa perspectiva de linguagem, a vivência - atividade mental - corresponde ao que o autor russo chama de discurso interior e a expressão - experiência - ao discurso dito, ou seja, ao enunciado concreto. Nesse sentido, o elo entre a base - organização social - e as superestruturas - sistemas ideológicos - se dá na ideologia do cotidiano, que é assumida como o universo dos discursos verbais, os enunciados concretos.

Sobre a vivência do discurso interior, o teórico russo afirma que a ideologia cotidiana se forma em camadas superiores e inferiores. Às camadas inferiores 
[...] pertencem todas aquelas vivências vagas, pouco desenvolvidas, que relampejam na nossa alma, bem como pensamentos e palavras ocasionais (VOLÓCHINOV, 2017b[1929], p. 213).

Já as camadas superiores são "aquelas que se encontram em contato direto com os sistemas ideológicos, são mais substanciais, responsáveis e possuem um caráter criativo" (VOLÓCHINOV, 2017b[1929], p. 213); "são capazes de transmitir as mudanças da base socioeconômica com mais rapidez e clareza" (VOLÓCHINOV, 2017b[1929], p. 213); e "acumulam as energias criativas responsáveis pelas transformações parciais ou radicais dos sistemas ideológicos (VOLÓCHINOV, 2017b[1929], p. 213). Além disso, são os estratos superiores da ideologia do cotidiano que, juntamente com os sistemas ideológicos - gêneros ideológicos - e a relação desses, torna possível a materialização dos gêneros discursivos do cotidiano.

A partir do ponto de vista das camadas superiores do cotidiano, Volóchinov (2017b[1929]) assume o enunciado como totalidade, isto é, como a real unidade da comunicação discursiva. E, ao assumir essa totalidade, Volóchinov (2017b[1929]) pontua elementos que se devem levar em consideração: a) o enunciado em sua totalidade só se realiza no fluxo da comunicação discursiva, em uma interação discursiva; b) a totalidade do enunciado é determinada pelas fronteiras que se encontram na linha de contato desse enunciado com o meio extraverbal e verbal - isto é, com os outros enunciados; c) a totalidade do enunciado se dá pelo auditório - a situação e o auditório forçam o discurso interior a atualizar-se em uma expressão exterior determinada e diretamente inserida no contexto cotidiano não enunciado, que é completado pela ação, ato ou resposta verbal dos outros participantes do enunciado; d) as formas e tipos de comunicação discursiva: os pequenos gêneros discursivos cotidianos. O próprio tipo de acabamento desses pequenos gêneros do cotidiano é determinado pelo atrito da palavra com o meio extraverbal e pelo atrito da palavra com a palavra alheia (VOLÓCHINOV, 2017b[1929]).

A partir do que é exposto sobre a questão do acabamento genérico dos enunciados, no item $d$, Volóchinov (2017b[1929]) distingue e revela possibilidades de conclusão genérica do discurso do cotidiano, ou seja, dos pequenos gêneros discursivos do cotidiano, que ele considera mais ou menos estáveis. Há um tipo de acabamento do gênero "correspondente aqui às particularidades ocasionais das situações cotidianas" (VOLÓCHINOV, 2017b[1929], p. 222), tais como uma ordem, uma pergunta completa. E há outro tipo de acabamento em que as "formas de comunicação cotidianas que sejam ao menos um pouco mais estáveis, fixadas pelo cotidiano e 
pelas circunstâncias" (VOLÓCHINOV, 2017b[1929], p. 222). Desses últimos, o autor elenca uma pequena tipologia que possui essa conclusibilidade genérica do discurso cotidiano, ou seja, os gêneros discursivos cotidianos mais estáveis: o bate-papo de salão: "leve e sem qualquer obrigação, onde todos se conhecem" (VOLÓCHINOV, 2017b[1929], p. 222); as conversas entre marido e mulher, irmão e irmã - gêneros familiares; as conversas entre pessoas heterogêneas que se reúnem em filas, etc. bate-papo entre vizinhos; e as conversas informais entre os trabalhadores no horário de almoço (VOLÓCHINOV, 2017b[1929]).

Para o teórico russo, cada situação cotidiana possui, nesse sentido, uma determinada organização do auditório e, portanto, um determinado repertório de pequenos gêneros cotidianos. E em todo lugar, o gênero cotidiano insere-se em uma determinada comunicação social, sendo um reflexo ideológico do seu tipo, estrutura, objetivo e composição social. Isto é, o gênero cotidiano é uma parte do ambiente social: da festa, do lazer, da conversa na sala de visitas, na oficina, etc., e em contato nesses ambientes, ganha limite e definição em seus aspectos interiores (VOLÓCHINOV, 2017b[1929]).

Volóchinov (2017b[1929]) desenvolve, a partir das postulações mencionadas, uma ordem metodologicamente fundamentada para o estudo da língua nessa perspectiva de uma sociologia marxista da linguagem, em que os gêneros discursivos do cotidiano têm lugar e destaque:

1) formas e tipos de interação discursiva em sua relação com as condições concretas;

2 ) formas dos enunciados ou discursos verbais singulares em relação estreita com a interação da qual são parte, isto é, os gêneros dos discursos verbais determinados pela interação discursiva na vida e na criação ideológica;

3) partindo disso, revisão das formas da língua em sua concepção linguística habitual (VOLÓCHINOV, 2017b[1929], p. 220).

Essa descrição parece ser construída para assumir, nessa perspectiva, um estudo que contemple o problema das formas do enunciado concreto cotidiano, como uma totalidade, isto é, como uma unidade real da comunicação discursiva.

Na seção seguinte, voltamo-nos à leitura e compreensão dos escritos no texto que é referência principal sobre o tema, "Os gêneros do discurso".

\section{Os gêneros do discurso: prática social e situada}

Nesta seção, nos voltamos ao texto clássico, "Os gêneros do discurso", para realizar uma incursão acerca do conceito de gêneros do discurso mobilizado, sobretudo, no que se refere à estrutura triádica dos gêneros do discurso. Dedicamo-nos, ainda, ao estudo do enunciado concreto, como a realidade fundamental da comunicação discursiva. 
Ponto inicial de reflexão sobre gêneros está ligado ao vínculo indissociável existente entre a utilização da linguagem e as atividades humanas nos mais variados campos. Bakhtin (2016[1952-53]) convoca o leitor a perceber os enunciados em sua função comunicativa como manifestações do discurso na interação discursiva.

$O$ texto postula que os gêneros do discurso "são tipos relativamente estáveis de enunciados" (BAKHTIN, 2016 [195253], p. 12, grifos do autor), e que é por meio dos enunciados - orais e escritos concretos e únicos que efetuamos o uso da língua, ou seja, a língua mobilizada na interação discursiva. Tais enunciados

[...] refletem as condições específicas e as finalidades de cada referido campo não só por seu conteúdo (temático) e pelo estilo da linguagem, ou seja, pela seleção de recursos lexicais, fraseológicos e gramaticais da língua, mas acima de tudo, por sua construção composicional (BAKHTIN, 2016[1952-53], p. 11-12).

Eis a estrutura triádica dos gêneros do discurso: conteúdo temático, construção composicional e estilo.

O primeiro elemento da estrutura triádica - conteúdo temático - diz respeito ao domínio de sentido do qual o gênero se ocupa. Contudo não se trata do assunto específico de um enunciado, mas sim do tema elegido. Afinal um determinado tema pode ser composto de diferentes assuntos que culminam em uma temática maior.

O segundo elemento - construção composicional - é o modo de organização e de estrutura do gênero, é a maneira como se dá a organização da materialidade do texto. Talvez seja o elemento mais mobilizado quando se pensa no conceito de gêneros discursivos, pois ele se refere às formas relativamente estáveis dos gêneros.

E o terceiro elemento - o estilo - está ligado à seleção de meios linguísticos selecionados para que haja compreensão responsiva ativa do enunciador pelo seu interlocutor. Bakhtin (2016[1952-53, p. 17]) nos revela que "todo estilo está indissoluvelmente ligado ao enunciado e às formas típicas de enunciados, ou seja, aos gêneros do discurso". Além disso, todo enunciado convoca um estilo individual, pois carrega a individualidade do falante, que se estabelece nas suas escolhas dos elementos linguísticos, revelando sua subjetividade, mas também carrega um estilo geral, próprio de algumas construções composicionais, em que tal reflexo de individualidade se torna mínimo, sendo mais propícios em gêneros discursivos ligados a certa forma padronizada, como, por exemplo, documentos oficiais, em que o estilo individual não faz parte do enunciado. Nas palavras do teórico russo (BAKHTIN, 2016[1952-53], p. 17-18),

[...] os estilos de linguagem não são outra coisa senão estilos de gêneros de determinadas esferas de atividades humanas e da comunicação. Em cada esfera existem e são empregados gêneros que correspondem às condições específicas de um dado campo". 


\section{E mais}

[...] uma função (científica, técnica, publicística, oficial, cotidiana) e certas condições de comunicação discursiva, específicas de cada campo, geram determinados gêneros, isto é, determinados tipos de enunciados estilísticos, temáticos e composicionais relativamente estáveis (BAKHTIN, 2016[195253], p. 17-18).

Tais elementos estabelecem, pois, uma interconexão da linguagem com a vida social, ou nas palavras do autor "a língua passa a integrar a vida através de enunciados concretos (que a realizam); é igualmente através de enunciados concretos que a vida entra na língua" (BAKHTIN, 2016[1952-53], p. 16). Afinal, os gêneros sempre estão ligados a uma esfera da atividade humana, revelando seu caráter social.

$\mathrm{E}$, por estarem ligados aos diversos campos da atividade humana, há uma grande heterogeneidade dos gêneros de discurso, visto que são infinitas as possibilidades da atividade humana e porque cada campo dessa atividade humana se dá a partir de um repertório de gêneros discursivos. Sobre a afirmação da grande heterogeneidade dos gêneros, Bakhtin (2016[1952-53]) assume que, até aquele momento, os estudos sobre gêneros discursivos nunca haviam sido verdadeiramente colocados em pauta. $\mathrm{O}$ que se tinha por tradição eram os estudos dos gêneros retóricos da tradição clássica, abordagem que não dava conta da natureza universalmente linguística do enunciado.

Dessa reflexão sobre a extrema heterogeneidade dos gêneros discursivos, o filólogo russo classifica os gêneros discursivos em primários e secundários. Os gêneros primários - simples - referem-se às modalidades de diálogo e comunicação discursiva imediata, isto é, são os diálogos do dia a dia - gêneros da conversa familiar e das atividades efêmeras cotidianas - advindos do simples convívio entre os sujeitos, e estão, dessa forma, ligados aos gêneros da oralidade, mas não somente (BAKHTIN, 2016[1952-53]).

Os gêneros secundários - complexos - manifestam-se das condições de um convívio cultural mais complexo e elaborado, e por tal característica estão mais ligados à escrita, porém, não unicamente. Manifestam-se como acontecimento artístico, em que os gêneros literários ganham destaque, porém não são os únicos gêneros complexos. $\mathrm{O}$ autor inclui nessa categoria, ainda, as pesquisas científicas e os gêneros jornalístico, religioso, jurídico, etc. Além disso, o autor revela que os gêneros secundários, em seu processo de formação, especialmente os romances, incorporam e reelaboram distintos gêneros primários, dando-lhes um caráter novo, isto é, eles perdem seu vínculo com a realidade imediata, e ganham uma elaboração ficcional, distanciando-se da comunicação discursiva imediata a que 
pertencem, passando de situações da vida real, do dia a dia, à ficção. Nessa perspectiva, Bakhtin (2016[1952-1953]) compreende os gêneros primários e secundários como interdependentes e complementares.

Logo, a diferença entre os gêneros primários e secundários é essencial. Portanto, pensar na natureza do enunciado significa que esta deva ser descoberta e definida por meio da análise de ambas as modalidades:

[...] apenas sob essa condição a definição pode vir a ser adequada à natureza complexa e profunda do enunciado [...], a orientação unilateral centrada nos gêneros primários redunda fatalmente na vulgarização de todo os problemas (BAKHTIN, 2016[1952-53], p. 15-16).

Ressaltamos, nesse excerto, que a questão principal como traço distintivo entre os gêneros primários e secundários nos parece ser à qual se vinculam os gêneros e suas relações, imediatas ou não, com a situação comunicativa. $\mathrm{E}$ que, mais que os diferenciar quanto a sua natureza, Bakhtin (2016[1952-53]) busca imbricá-los, revelando, assim, a historicidade no desenvolvimento dos gêneros do discurso.

Sobre o surgimento e o desenvolvimento histórico dos gêneros do discurso, destacamos que, embora normalizadores - estáveis -, os gêneros possuem maior plasticidade e são mais ágeis do que as formas da língua - orações. É o que Bakhtin (2016[1952-53]) revela ao dizer que os gêneros são tipos relativamente estáveis de enunciados, ou como compreende Faraco (2009, p. 127), o teórico russo, ao assumir a expressão relativamente estáveis:

Está dando relevo, de um lado, à historicidade dos gêneros; e, de outro, à necessária imprecisão de suas características e fronteiras. Dar relevo à historicidade significa chamar a atenção para o fato de os tipos serem definidos de uma vez para sempre, eles não são apenas agregados de propriedades sincrônicas fixas, mas comportam contínuas transformações, são maleáveis e plásticos, precisamente porque as atividades são dinâmicas, e estão em contínua mutação.

Ou seja, os gêneros evoluem, transformam-se, surgem, desaparecem, são absorvidos por outros. Para Bakhtin (2016[1952-53]), o desenvolvimento e a transformação dos gêneros, bem como o surgimento de novos gêneros é dado pelo desenvolvimento e complexificação nos diversos campos da atividade humana e da comunicação, e por novas motivações sociais decorrentes dessa complexidade, que se concretizam nas interações sociais.

Ainda sobre as transformações dos gêneros e complexificação da realidade, ligadas à historicidade dos gêneros discursivos, Fiorin (2016, p. 76) complementa que "o gênero somente ganha sentido quando se percebe a correlação entre forma e atividades". E com isso, os gêneros não são "um conjunto de propriedade formais isolado de uma esfera de ação, que se realiza em determinadas coor- 
denadas espaço-temporais, na qual os parceiros da comunicação mantêm certo tipo de relação" (FIORIN, 2016, p. 76). $\mathrm{Na}$ verdade, os gêneros são "meios de apreender a realidade" (FIORIN, 2016, p. 77). Outro aspecto revelador indica que mudanças na sociedade pressupõem mudanças nas maneiras de dizer, nos gêneros, ou seja,

[...] novos modos de ver e de conceptualizar a realidade, implicam o aparecimento de novos gêneros e a alteração dos já existentes. Ao mesmo tempo, novos gêneros ocasionam novas maneiras de ver a realidade (FIORIN, 2016, p.77, grifos nossos).

Na segunda seção do manuscrito, Bakhtin (2016[1952-53]) realiza uma discussão mais ampla e mais aprofundada sobre o enunciado concreto como unidade real da comunicação discursiva, opondo-o às palavras e às orações como unidades da língua, que era a concepção vigente de abordagem linguística, mantendo a perspectiva do Círculo de Bakhtin de estabelecer uma interlocução com as correntes filosóficas e linguísticas de cada escrito além de uma crítica e uma superação dos conceitos vigentes.

A partir dessa perspectiva dialógica e enunciativa da linguagem, o teórico (BAKHTIN, 2016[1952-53]) passa a refletir sobre o enunciado e seu papel na comunicação discursiva e seus tipos, os gêneros de discurso, produzindo uma definição para enunciado concreto. Uma primeira definição de enunciado é "a real unidade da comunicação discursiva" (BAKHTIN, 2016[1952-53], p. 28), pois, para o autor, o discurso - língua em sua integridade concreta e viva - só existe nos enunciados, proferidos por determinados falantes, de diferentes esferas da atividade humana, dentro de uma situação comunicativa, e que fora dessa forma, não pode existir. $\mathrm{O}$ "discurso sempre está fundido em forma de enunciado" (BAKHTIN, 2016[1952-53], p. 28).

Bakhtin (2016[1952-53]) afirma que os enunciados são heterogêneos, por seu volume, seu conteúdo, e sua construção composicional, possuindo peculiaridades estruturais que o tornam únicos no grande fluxo discursivo, mas também produz limites precisos para esses enunciados; tal limite se constitui em três peculiaridades que compõem os enunciados concretos.

A primeira peculiaridade refere-se à alternância dos sujeitos do discurso: a alternância estabelece-se tanto entre interlocutores em uma relação face a face, ou em uma conversa cotidiana, como também no interior do enunciado, por convocar o discurso de outros falantes da comunicação discursiva. Bakhtin (2016[1952-53]) afirma que a alternância dos sujeitos se dá por meio da réplica. Tais réplicas são chamadas de respostas - atitudes responsivas - a enunciados anteriores e também aos posteriores. A réplica revela as relações dialógicas que determinam um o acabamento específi- 
co do enunciado concreto (BAKHTIN, 2016[1952-53]).

A segunda peculiaridade é a conclusibilidade - acabamento do enunciado: uma espécie de aspecto interno de alternância dos sujeitos do discurso, em que "essa alternância pode ocorrer precisamente porque o falante disse (ou escreveu) tudo o que quis dizer em dado momento ou sob dadas condições" (BAKHTIN, 2016[1952-53], p. 35). A conclusibilidade - que assegura a possibilidade de resposta, de compreensão responsiva - é determinada por categorias específicas: a) exauribilidade semântico-objetal; b) o projeto de discurso ou vontade de discurso do falante; c) as formas típicas da composição e do acabamento do gênero (BAKHTIN, 2016[1952-53]).

A terceira peculiaridade constitutiva é a relação do enunciado com o próprio falante - locutor - e com outros participantes da comunicação discursiva: a concepção dialógica de linguagem proposta por Bakhtin e o Círculo pressupõe sempre o outro como constitutivo do discurso, logo os sujeitos parceiros da comunicação discursiva são imprescindíveis na composição do enunciado, pois, conforme aponta Bakhtin (2016[195253]), a escolha dos meios linguísticos e do gênero discursivo é determinada pela vontade - ideia - do sujeito do discurso em relação aos sujeitos envolvidos na interação discursiva. Logo, a composição e o estilo do enunciado não são determinados somente pela relação valorativa do enunciado com elemento semântico de seu discurso, isto é, para determinar o estilo do enunciado, não se pode considerar apenas a visão de mundo do seu falante, nem tão pouco sua visão de mundo, é de suma importância, que se considere a relação entre o locutor e seus interlocutores de uma determinada interação discursiva (BAKHTIN, 2016[1952-53]).

A definição de enunciado concreto a partir do que se estabelece pelas peculiaridades constitutivas, toma forma por meio dos gêneros em uma determinada esfera de comunicação discursiva, pois é o gênero que garante uma estabilidade relativa e uma determinada especificidade, pois, para Bakhtin, toda comunicação se dá por meio de gêneros,

[...] falamos apenas através de certos gêneros do discurso, isto é, todos os nossos enunciados têm formas relativamente estáveis e típicas de construção do conjunto (BAKHTIN, 2016[1952-53], p. 38, grifos do autor).

$\mathrm{O}$ autor exemplifica que em qualquer interação - do bate-papo descontraído ao tratado científico - moldamos e adaptamos o nosso discurso, a partir de certas formas relativamente estáveis de enunciado, isto é, de gêneros. E postula:

[...] esses gêneros do discurso nos são dados quase da mesma forma que nos é dada a língua materna, a qual dominamos livremente até começarmos o estudo teórico da gramática (BAKHTIN, 2016[1952-53], p. 38). 
Nesse fragmento axiológico da segunda seção, o teórico russo assume que, na perspectiva dialógica da linguagem, falamos somente por meio de enunciados concretos, que se materializam em formas de gêneros, que emanam de uma dada esfera de atividade humana e em uma determinada interação social, refutando a perspectiva de que falamos por meio de orações isoladas - como unidades da língua -, ao contrário, selecionamos as formas abstratas da língua para falar por meio de enunciados. Em suma, para Bakhtin, "aprender a falar significa aprender a construir enunciados" (2016[1952-53], p. 39).

Nessa perspectiva, conforme Bakhtin (2016[1952-53]), falamos por meio de gêneros, de modo que a língua materna não é por nós apreendida por meio de dicionários e gramáticas, mas é por meio de enunciados concretos que ouvimos, apreendemos e reproduzimos na comunicação discursiva viva, ou seja, na interação. E se apreendemos a língua por meio de gêneros, há gêneros em que dominamos mais e outros menos, visto que muitas são as esferas de atividade humana e de discursos que são convocados em uma determinada interação discursiva. Por isso, quanto mais dominamos os gêneros,

[...] maior é a desenvoltura com que os empregamos e mais plena e nitidamente descobrimos neles a nossa individualidade (onde isso é possível e necessário), refletimos de modo mais flexível e sutil a situação singular da comunicação - em suma, tanto mais plena é a forma com que realizamos o nosso livre projeto de discurso (BAKHTIN, 2016[1952-53], p. 41).

Bakhtin estabelece, portanto, uma segunda definição para o enunciado concreto e suas formas típicas, que são a verdadeira forma de comunicação discursiva, pois é somente por gêneros que dizemos, isto é, mobilizamos nosso discurso em uma determinada interação.

Após essa incursão teórica, a fim de construir um conceito de gênero de discurso, convocando noções e princípios importantes à temática desenvolvida ao longo deste artigo, encaminhamo-nos às considerações finais, onde buscamos cumprir o objetivo deste artigo, qual seja, de mostrar que o conceito de gênero do discurso em Bakhtin e seu Círculo é construído em um conjunto de textos e obras, não se restringindo ao manuscrito clássico do final da década de 50 .

\section{Considerações finais}

De maneira sintética, o que depreendemos dessa incursão teórica é que nem só da "fórmula mágica" sobrevive o conceito de gênero do discurso para Bakhtin e o Círculo, isto é, a estrutura triádica - conteúdo temático, construção composicional e estilo - não parece ser a única forma para análise e interpretação de um gênero do discurso. Além disso, acreditamos que a perspectiva voltada somente à concepção triádica acaba por renegar os gêneros, como prática social 
e situada, o que entendemos, contradiz o próprio conceito de língua, na perspectiva Bakhtiniana, que assume que a interação discursiva é a realidade fundamental da linguagem e a língua só se realiza por meio de enunciados concretos que se estabilizam em gêneros discursivos de diferentes esferas de atuação humana. Nessa perspectiva, um conceito de gênero de discurso filiado à perspectiva teórica desenvolvida pelo Círculo de Bakhtin deve levar em consideração outros elementos de grande relevância aos gêneros, como: contexto de produção do gênero; a esfera de atividade humana que está ancorado o discurso que se materializa nos gêneros; a perspectiva espaço-temporal em que se situa o gênero com acontecimento social; os sujeitos envolvidos na enunciação; o auditório social; todas as relações dialógicas constitutivas do enunciado; ou seja, tudo o que se refere à produção, circulação e recepção de um gênero do discurso, em uma determinada interação discursiva.

A perspectiva linguístico-filosófica de Bakhtin e o Círculo possibilita, portanto, estudar os gêneros do discurso como prática social e situada, que emergem das relações de interação, as quais se realizam nas relações dialógicas geradoras de sentido. Dessa forma, estudar os gêneros é compreender as relações dialógicas entre os textos, os discursos ditos, entre os sujeitos envolvidos na interação discursiva; é compreender quem diz, por que diz e, mais importante, para quem diz.
Esperamos, com esse estudo teórico, não dar conclusibilidade a tema tão caro no conjunto do pensamento desse grande filósofo da linguagem. Contentamo-nos se pudermos contribuir, de alguma maneira, para mostrar que para compreender o conceito de gêneros do discurso é preciso ler além do manuscrito homônimo que popularizou o autor, especialmente no campo educacional.

\section{Why it is necessary to deepen the concept of speech genres?}

\section{Abstract}

This article aimed to revisit the concept of speech genres, regarding the perspective of The Bakhtin Circle, in order to, through this theoretical incursion, go further in the concept of gender in a group of texts, besides the classical manuscript that has popularized it. The study reveals that the concept of speech gender for Bakhtin and The Circle assumes a triad structure - thematic content, compositional construction and style, as essential part of the concept, but other aspects might be considered, such as the context of gender production, the axis in which human activity is anchored in the speech that takes part in genres, the subjects who are involved in the interaction, the social audience, the dialogical relationships that constitute the enunciation.

Keywords: Speech genres; dialogical relationships; interaction; enunciation. 


\section{Nota}

1 Não abordaremos a questão da polêmica das autorias contestadas de obras do Círculo de Bakhtin, temática que entendemos ter sido discutida amplamente no universo acadêmico e nas publicações dos últimos anos.

\section{Referências}

BAKHTIN, Mikhail M. O discurso no romance. In: Questões de Literatura e estética: a teoria do romance. 6. ed. São Paulo: Hucitec, 2010, p. 71-210.

BAKHTIN, Mikhail M. Os gêneros do discurso. Tradução de Paulo Bezerra. São Paulo: Editora 34, 2016.

BAKHTIN, Mikhail M. Peculiaridades do gênero, do enredo e da composição das obras de Dostoiévski. In: Problemas da Poética de Dostoiévski. Tradução de Paulo Bezerra. 5. ed. Rio de Janeiro: Forense Universitária, 2013, p. 115-206.

BRAIT, Beth; PISTORI, Maria H. C. A produtividade do conceito de gênero em Bakhtin e o Círculo. ALFA: Revista de Linguística. v. 56, n. 2, 2012, p. 371-401. Disponível em: $<$ https://periodicos.fclar.unesp.br/alfa/article/ view/5531>. Acesso em: 10 mar. 2019.

FARACO, Carlos A. Linguagem \& Diálogo: as ideias linguísticas do círculo de Bakhtin. São Paulo: Parábola Editorial, 2009.

FARACO, Carlos A. O problema do conteúdo, do material e da forma na arte verbal. In: BRAIT, Beth. (Org.). Bakhtin, dialogismo e polifonia. São Paulo: Contexto, 2013. p. 95-112.

FIORIN, José L. Introdução ao pensamento de Bakhtin. 2. ed. São Paulo: Contexto, 2016.

MEDVIÉDEV, Pável N. Os elementos da construção artística. In: $O$ método formal nos estudos literários: introdução crítica a uma poética sociológica. Tradução de Sheila Camargo Grillo e Ekaterina Vó- lkona Américo. São Paulo: Contexto, 2016, p. 193-207.

MORSON, Gary S.; EMERSON, Caryl. 7. Teoria dos Gêneros. In: $\mathrm{Mi}$ khail Bakhtin: criação de uma prosaística. Tradução de Antonio de Pádua Danesi. São Paulo: Edusp, 2008, p. 287-322.

SÉRIOT, Patrick. Volo $\square$ inov e a filosofia $d a$ linguagem. Tradução de Marcos Bagno. São Paulo: Parábola Editorial, 2015.

VOLÓCHINOV, Valentin. O problema da relação entre a base e a superestrutura. In: . Marxismo e filosofia da linguagem: problemas fundamentais do método sociológico na ciência da linguagem. (Círculo de Bakhtin). Tradução de Sheila Grillo e Ekaterina Vólkona Américo. São Paulo: Editora 34, 2017a, p. 103-114.

VOLÓCHINOV, Valentin. A interação discursiva. In: _. Marxismo e filosofia da linguagem: problemas fundamentais do método sociológico na ciência da linguagem. (Círculo de Bakhtin). Tradução de Sheila Camargo Grillo e Ekaterina Vólkona Américo. São Paulo: Editora 34, 2017b, p. 201-226. 